\title{
Folk Literature Production and People's Daily Life in the Hinter Land of Mount Ailao
}

\author{
Kaiwan Xiong \\ Social Management College \\ Kunming University \\ Kunming, China
}

\begin{abstract}
As the historical evidences of the national cultural inheritance in a country, the folk literatures contain rich historical and cultural traditions of the country and the people. The cross-clan literature production is a cultural practice for the mutual exchanges and mutual promotion of the national culture. Based on a folk literature survey in Wengang Village, Jiujia Town, Zhenyuan County in the hinterland of Mount Ailao, this thesis studies the relationship between the folk literature production $\&$ transmission and the people's daily life. It concludes that while produced and transmitted along with people's daily life, folk literatures also regulate and construct people's daily life and remain the basis for the innovation of local cultural traditions.
\end{abstract}

Keywords-folk literatures; hinterland of Mount Ailao; morality book; cultural tradition

\section{INTRODUCTION}

Folk literature is a historical basis for the inheritance of national culture, which contains the rich historical and cultural traditions of a country and nation. The production and dissemination of folk literature, on the one hand, helps us understand the style of people's life and the concepts that support people's daily life. In academic world, the significance and value of folk literature have long aroused the attention of researchers in various fields. In the 1920s, Gu Jiegang's study of Meng Jiangnv's story was an excellent example. After the emergence of Annales School in the west, many historians made full use of the first-hand information of folk literature to construct many classic case studies in the field of history. For example, Marcel Granet's "Festivals and Ballads of Ancient China" made in-depth research on religious customs and ethnic beliefs of ancient Chinese with the help of the Chinese classical literature "The Book of Songs" and the presently preserved literature and ballads. [1] $\mathrm{Ou}$ Danian's "A study of Chinese folk religious sects" analyzes the ideological basis of people's daily life by using great deal of folk literature, holding that cultural change and historical development of China since modern times can be observed through ordinary people's daily life and customs and habits presented by the almanac, contracts, and inscriptions and other materials. [2] Elman analyzed the relationship between the thought and social changes in late Imperial Chinese and concluded that the collapse of the Chinese intellectual world had its endogenous reasons. [3] Wang Zhenzhong, and Bian Li published a large number of very influential articles through the collection of Huizhou documents. It can be said that the investigation and arrangement of folk literature has become a new trend in the research and innovation of Chinese intellectual history, anthropology, folklore and history.

Mount Ailao, an important mountain in the southwestern part of Yunnan Province, is the boundary of YunnanGuizhou Plateau and Hengduan Mountains. The vast mountainous area in the south of the main peak of Mount Ailao, Daxueguo mountain, the west of Yuanjiang and the east of Lancang River, including Zhenyuan, Jingdong, Mojiang and Jinggu of Pu'er city and Xinping of Yuxi of present-day have always been described as hinterland of Mount Ailao by historians and geographers. Historically, this area is turned to the three administrative units directly under the Central Government, namely "Jingdong, Zhenyuan and Xinping" because of ethnic mixture, sluggish economic and social development and difficulties in social control. After the middle and late Qing Dynasty, a large number of Han people immigrated to hinterland of Mount Ailao. Due to the competition of living resources such as land, water and forest, ethnic conflicts in the area were greatly intensified. The struggle of Dai Chieftain opposing bureaucratization of native officers and revolt of ethnic minorities including $\mathrm{Li}$ Wenxue and Tian Silang opposing Han dynasty broke out successively. Since then, the area has been in the situation of thief haunting and social chaos. In order to promote local development, the Han intellectuals and the elites of all ethnic groups actively promote the local cultural construction. In this process, a large amount of folk literature has been produced, which still has great referential significance to today's social construction. Since 2010, we have conducted more than ten times of literature surveys in Wengang Village, Jiujia Town, Zhenyuan County in the hinterland of Mount Ailao. We collected more than 400 kinds of folk literature, over 100 oral materials, over 40 engravings, and more than 60 inscriptions and documents. We attempt to explore the relationship between the production and dissemination of folk literature and people's daily life from the perspectives of political districts and local history, and explain how the textual tradition of folk literature affects the folk traditions of people's daily life. 


\section{THE HiSTORICAL CAUSES FOR FOLK LITERATURE IN THE HINTERLAND OF MOUNT AILAO}

The formation of folk literature in the hinterland of Mount Ailao is directly related to the thought of humanistic education generated after Han people's migration. The couplet that can be found everywhere is full of rural social ideals of part-time learning and self-study such as "studying while farming is a family heirloom and the life of books is long", "Brothers feel happy when Jing tree bloom, and children write as a livelihood as a tax-free field", "the family who believe in Confucianism should believe books since books tell the truth. The elegant words are poetry and rituals, and only the article cultivate one's mind", and "Taoism in the people while cultivation relies on individuals, and blessing last long because of the article". Such simple and plain concept on the one hand is the basis for the nation keep a foothold in this area for long term. They should spend leisure time of slack season on the approaching of culture and education to ensure the norms and virtues of individual behavior. More importantly, by linking culture and education with field thought, the consolidating thought of poetry helping passing the generation is formed, so people will send their children to attend school even if they need to "smash the pan and sell them".

In addition, the Han people strengthen their culture as the culture, which is conducive to maintaining their own cultural identity in the multi-ethnic communities without confusion. So far, there is the saying "if three generations do not study, they will become barbarians" in local folk. In the local context, the barbarians do not refer to the various ethnic groups in the surrounding regions, but the rude and unreasonable behaviors. Studying is the inherent logic of the development of civilization, and appreciating education and respecting classics is the way for a family to live and grow. At the same time, the rich forests in the hinterland of Mount Ailao and the Broussonetia papyrifera in the forest provide the conditions for paper production and woodblock printing technique. Woodblock printing as an ancient method of literature production was long-term used in the hinterland of Mount Ailao. Until 1940, the people of the three villages of Wengang, Diankeng and Mengzhen of Jiujia Town printed 12 persuasion books entitled "orange osmanthus record" by woodblock printing. Previously, Azure Cloud Temple and Tianhua Temple have inscribed the books such as "Three Religions rounded", "Causal classics", "boat of three telents", and "Liberation".

The localization of Taoism rituals makes folk literature in the hinterland of Mount Ailao rich and diverse. Ritual was originally conducted in Taoist temples. However, under the impetus of the Han intellectuals, it became a fixed program for local residents to celebrate weddings and funerals, which runs through people's lives and deaths. In the using of ritual document, it is inevitable to improve it according to the local conditions so that this kind of literature has the characteristics of the region and the times. Taking rid star ceremony as an example, the ritual sections are inviting the God, chanting "all goods scriptures", burning lights to praise stars, dissolving grievance and releasing knot, calling the soul, and returning holy. In these sessions, Qiwen is a piece of key words. It is necessary to make clear the difficulties and prayers that the family faces and the effects that they hope to gain through ceremony. All the contents are related to family life. In this way, the production of ritual document becomes an activity of cultural creation and symbolic interaction.

Influence of hidden good deeds thought is as follow. The term "hidden good deeds" means silently stabilizing, namely converting good deeds into a good deed to the doer's credit in the next world. In traditional Chinese society, hidden good deed is a social capital that can be accumulated, transferred, converted, and predicted. It plays the role of showing nature and cultivating moral life in the construction of social order. "Printing scriptures" itself is a way of doing good deeds and accumulate virtue, as $\mathrm{Gu}$ Tingbiao, the person who makes comments for "orange osmanthus record" points out:

Today's scriptures generally refer to the sages, Buddhas and training of the three religions. Creator declares what are never seen and heard and announces what has been seen and heard. Printer prints what can't be written completely into series and spread them all over the world. Therefore, exhortations are only enough to move people's perception of the moment, but the printing that can spread widely can sober the world, gain wide good deeds to the doer's credit in the next world, and feed the boundless. Those who have the power publish literature while those who don't record. How can you say this is not a determined effort? [4]

Printing can open the world's obfuscation and spread widely. "Although the descendants are stupid, the book cannot be read", but if there is no printing books, they have nothing to read. It is generally believed by the local people that the human and material resources invested in the printing of scriptures are the embodiment of human's dedication and obedience to God. The local ethnic groups admire the Han culture and actively learn from the Han people. When printing scriptures, they gave out whatever they had, which promoted the production of folk literature.

\section{TYPES AND USAGE OF FOLK LITERATURE IN THE HINTERLAND OF MOUNT AILAO}

The folk literature in the hinterland of Mount Ailao can be roughly divided into folk rituals literature, funeral oration, folk morality books and their block carvings, squires' collection, and stone inscriptions in terms of form.

The rituals literature is the most abundant kind in the literature in the hinterland of Mount Ailao. In the more than 400 current collected articles, about 250 pieces are rituals literature. The ritual literature can be divided into three categories of repentance, clerical class and action book. Repentance is an important part of ritual activities. It is preach of supernatural power of gods and divine grace, and its main social function is persuasion. There is always the saying "read the scriptures to the living" in folk, of which the thought of accumulating good morality has important significance. The repentance literature such as "sculpture of all goods" "gratitude sculpture of blood bowl in Wenchang", "Blood River" "liberation", "warrior sculpture", "yin and yang sculpture", "Jade Emperor", "Tellus Mater", "Five man 
sculpture", "Ten Kings sculpture", "Wenchang retreat Dadong sculpture", "blood River Repentance", "Ten wangbao Repentance", "Big Dipper Repentance" and so on, are mainly popularized by handwritten. Clerical class is the letter written to the gods in the ritual activities, including memorial, sacrifice article, analysis, and certificate. The common instruments in Jiujiazhen mainly include "three religions have the same origin" and "movement of the ten palace" and so on. Action book is the book used to follow in ritual, mainly including "open the road and cover coffin", "scatter flowers", "Shifu call the soul", "big lament", "burning lamp to praise star", "sentenced to disperse diaodou", "condemn Pan", "greeting wedding action", "sent to death", "save dragon" and so on. The Luan chapter is a product of ritual activities, of which the content is the success of the ceremony and possible problems. Nowadays "Great Temple of Wengang Temple Great chapter" and "Lingguan Temple Great General Chapter" are related to Purdue activities.

Folk morality books and their woodblock printing is as follow. Morality books are popular literature that promotes traditional ethics. The content integrates the thoughts of Confucianism, Buddhism and Taoism. It is a media that guides civil society to have the thought and behavior of doing good deeds to accumulate virtue, spread hidden good deeds and farming by the way of karma. The popular and powerful language has a great influence on people's daily life and is a folk tradition that cannot be killed Since the middle and late Qing dynasty, morality books printed in Jiujia town includes "orange osmanthus record", "Avalokiteshvara sculpture", "boat for three talents", "Old emperor record", "Three Religions rounded", and "Cause classics " and so on. Taking "orange osmanthus record" printed on Juxian altar as an example, the whole book has been engraved for more than 30 years. Both the Han people and the neighboring ethnic groups participated in the publication of the morality book, which is a culture achievement jointly created by the Han nationality and the ethnic minorities.

In squire paper, squires are folk intellectuals. Mr. Fei Xiaotong pointed out that squires are the leaders of rural community construction in China, as well as the main producer and disseminator of folk culture. Squire leads the local construction, such as the construction of schools, excavation of ditches, inscription of morality books, and building terraces and so on, they are also the main organizer and performer of rituals. The squire papers generally have their own personality. The common daily lives and rural life style can be seen in some inadvertently written verse and the caption. Since the middle and late Qing Dynasty, there are many famous squires and much literature in Jiujia Town. Many kinds of works such as "Geographic Longquan Sha Shui", "spring paper", and "Everyday Letters" are collected. Among them, the author of "Everyday Letters" is Peng Zhaoyuan. The book is the record about the civil group Niu Chonghui mediating civil dispute, which has strong social and historical values.

In addition, common folk literature includes white head paste record, account book for weddings or funerals, merit books, and genealogies and so on. These documents are an important basis for understanding people's thoughts and behaviors. Among them, white head paste is the humorous poem that people who just become literate carve on bamboo and on the wall or spread orally in the spare time of farming, which is funny with strong expressive force. For example, "Zhang Huashan burns bamboo by fire and cries after burning" and "brother carries salt on back and sings salt song. His long neck is favorable for uphill. Sisters are waiting for salt at home and their hair chaos like hen's nest" not only have the value of folk literature study, but also has the meaning of social life history, from which we can see people's heart and the natural law.

\section{The CONSTRUCTION OF PEOPLE'S DAILY LIFE BY FOLK LITERATURE}

Folk literature is the carrier that regulates the rigor and sacredness of daily life. Both religious ritual literature and general readings are considered as inviolable ontology of meaning. None of the words can be violated because "one word is one sculpture". Through the folk literature, the mainstream thoughts of traditional society and people's daily life and their ritual performances permeate each other, creating a mutual invention mechanism between folk traditions and textual traditions. Mutual invention of texts and folk traditions is the basic motive force for the cultural development in the hinterland of Mount Ailao. Various types of rituals held regularly every year, continuous publication cause, and wise words and exemplary conduct spread in folk continue to inspire people's good deeds in all aspects of social life.

Folk literature standardizes the society by ethics and morality, and takes the heart for good and mellow custom as the foothold of social integration. With the production of folk literature and prevalence of cause and effect, hidden good deeds, farmland, and moral integrity, it is universally accepted by all ethnic groups and efforts have been made between ethnic groups to jointly build a local society. At the same time, the folk literature builds the sharing effect based on territorial community, which lays the foundation for the all ethnic groups to equally contact, build the local community and share development. Ethnic groups crossed the border of nations to produce a cross-border text that promotes the coexistence and common prosperity of the cultures of all nationalities in the hinterland of Mount Ailao.

Folk literature production and local social construction promote each other. The folk literature is the result of textual tradition absorbing and creating folk tradition and the newly produced text constantly provides the basis for social changes. Although ordinary people find it hard to read the literature themselves, various types of rituals held regularly every year, continuous publication cause, and wise words and exemplary conduct spread in folk continue to inspire people's good deeds in all aspects of social life, which promoted the social construction of the hinterland of Mount Ailao and its the impact has continued until today. The folk literature regards "benevolence", "conscience", "compassion" and "shamelessness" as the criterion for construction of social order and takes the heart for good and mellow custom as the foothold of social integration. The 
good deeds including giving coffin, helping the poor, repairing road, building bridges, lighting night, protecting the environment, and liberating animals are practiced extensively by villagers. With the publication of folk literature, it is generally believed that the integration of the value system of morality refers to the qualification of sharing the achievements of local society construction. From the perspective of our own destiny, "life is generated by the heart and appearance is created by heart", and "good deeds and evil deeds will lead to certain result and doing good or bad is based on the situation". Therefore, to know the nature and spare no efforts to live has become everyone's responsibility.

The production of folk literature has promoted the efforts of all ethnic groups to jointly build local society. Since 1901, the ethnic groups in Jiujia Town have built 17 bridges, among which the Storm Bridge constructed in 1914 has become the famous scenery on the ancient Tea Horse Road. The small street stone bridge constructed in 1930 is built by the local ethnic groups with plaster made from glutinous rice in the absence of cement and other modern building materials, which has been used so far. In addition, some new good customs and habits are also gradually formed in joint development, such as the custom of collective road repairing every year on May 28 of the lunar calendar and the custom of holding Niu Chong meeting to discuss village rules and regulations from time to time.

Constructs the sharing effect based on territorial community. The construction of social order itself pursues the civilized scale. In other words, people of any era have tried to construct a symbolic system that can represent the scale of their civilization. In the hinterland of Mount Ailao in mid-to-late period of the Qing dynasty, the Qing government implemented bureaucratization of native officers, sending flowing officers to govern local place. The requirements for the scale of civilization is to unite all ethnic groups in the far and near, high and low, and close and distant empire civilization system, namely "conversion". That is changing their customs to unify them in China. There is a process of domestication of "different" culture. Although the production of folk literature can't manifest the cultural forms of all ethnic groups on an equal standpoint, it has laid the foundation for all ethnic groups to have equal exchanges, jointly build local communities and share development. Ethnic groups crossed the border of nations to produce a cross-border text that promotes the coexistence and common prosperity of the cultures of all nationalities in the hinterland of Mount Ailao.

\section{CONCLUSION}

Social science researchers not only need to study the social ecology, but also should study the social mentality. Social mentality itself has its own structure, and it is also a construction process. The so-called construction, simply put, is that the people assimilate the problems they encounter in the living environment to their proper lifestyles so as to form new adaptation strategies or mechanisms. This is the fundamental reason why the Chinese local community culture can continue endlessly. Ignoring the construction of social mentality and blindly guiding people's daily life with new concepts and new ideas is the direct reason why it is hard for China's rural construction to achieve the desired results in the past 20 or 30 years.

Through the study of the relationship between the folk literature and people's daily life in the hinterland of Mount Ailao, it is found that there exists a mechanism of mutual infiltration and enlightenment between textual tradition and folk tradition in the hinterland of Mount Ailao. The existence of this mechanism has continuously evolved into a ritual space for the people to cultivate good morality, accumulate hidden good deeds, keep honesty and filial piety, benefit people and things, and resolve grievance and also contributed to the formation of inter-ethnic solidarity and inter-ethnic texts. On the one hand, due to certain cultural traditions, folk literature is produced and disseminated with unfolding of people's daily life. On the other hand, folk literature records, regulates and constructs people's daily life.

The folk literature has complex connotations at several aspects in the lives of people in the hinterland of Mount Ailao. It is the inheritance path of family tradition of farming civilization in China over thousands of years and is given moral, social and religious meanings. Even under such conditions of the "official career" of "A good scholar will make an official" being abolished due to science and technology, poverty, war, the dual identity system in urban and rural areas and the Great Cultural Revolution, civil intellectuals can also make full use of the power of knowledge to achieve self-actualization and self-fulfilling. The cultural tradition in the hinterland of Mount Ailao, still maintained a highly integrated impetus because of the folk literature.

\section{REFERENCES}

[1] Marcel Granet, tr. Zhao Binxiang. Festivals and ballads in Ancient China. Guilin: Guangxi Normal University Press. 2005, 11.

[2] Ou Danian. A study of Chinese folk religious sects. Shanghai: Shanghai Chinese Classics Publishing House, 1993,7.

[3] Benjamin Elman. tr. Zhao Gang. From down-to-earth learning to Neo-Confucianism - observation of Thought and Social Change in Late Qing Dynasty Empire. Nanjing: Jiangsu People's Publishing House, 1995

[4] Volume IV of "Orange osmanthus record", fairy altar book of new village, is reserved in Diankengling officer temple of Jiujia town in Zhenyuan County, Yunnan Province. 